\title{
Sociodemographic predictors of success in smoking intervention
}

\author{
E Monsó, J Campbell, P Tønnesen, G Gustavsson, J Morera
}

\begin{abstract}
Aim-To examine the role of sociodemographic factors as predictors of sustained smoking cessation for the population who volunteer to participate in intervention programmes.

Method-Data for the 3575 smokers who participated in the CEASE (collaborative European anti-smoking evaluation) trial, a European multicentred study that used transdermal nicotine patches as an adjunct to smoking cessation in the chest clinic, were analysed. The effects of age, sex, smoking habit, socioeconomic status (housing conditions, education, and employment), disease, smoking habits of relatives, and baseline markers of tobacco use on sustained smoking cessation (self-reported abstinence and expired carbon monoxide $<10$ parts per million) were assessed using logistic regression modelling (odds ratio (OR), 95\% confidence interval (CI)).
\end{abstract}

Results-477/3575 smokers were sustained abstainers one year after the intervention (overall success rate $13.3 \%$ ). In the univariable logistic regression models an effect of active treatment on smoking cessation was observed (OR 1.50, 95\% CI 1.15 to 1.96 ), and additional effects on outcome were found for age (OR 1.02, 95\% CI 1.01 to 1.03 ), sex (men $v$ women: OR $1.38,95 \%$ CI 1.14 to 1.68 ), housing conditions (OR $1.43,95 \%$ CI 1.25 to 1.65 ), current respiratory (OR $0.79,95 \%$ CI 0.67 to 0.92 ) or cardiac disease (OR $0.46,95 \%$ CI 0.28 to 0.75), and markers of tobacco use (cigarettes per day: OR $0.79,95 \%$ CI 0.69 to 0.90 ; expired carbon monoxide: OR $0.98,95 \%$ CI 0.97 to 0.99$)$. Education and employment did not have a significant effect on the outcome. The effect of the variables associated with success in smoking cessation persisted after adjustment for covariates.

Conclusion-Age, sex, and housing conditions have a major effect on smoking cessation in European smokers participating in smoking cessation programmes. (Tobacco Control 2001;10:165-169)

Keywords: cessation; sociodemographic predictors

Age, sex, socioeconomic status, and nicotine dependence are well defined determinants of success in smoking cessation for the general population. ${ }^{12}$ The impact of these factors on success rates, however, has rarely been investigated for participants in smoking intervention programmes. The wide range of abstinence rates attained in these programmes has been attributed to non-specified characteristics of the target population or to methodology. In smoking cessation the nicotine patch and other nicotine products have proven useful, as shown by increases in the proportion of smokers who quit. $^{34}$ The limited information on the predictors of success in smoking intervention makes it difficult to adjust programmes to target populations, a necessary requirement for achieving the maximum possible benefit, under the assumption that populations with specific sociodemographic characteristics would need to be targeted appropriately, independently of their degree of motivation. ${ }^{56}$

In the present study we have examined the role of different sociodemographic factors as predictors of successful smoking cessation in the sample of smokers from 17 European countries that were enrolled in the CEASE (collaborative European anti-smoking evaluation) trial, a study that examined the effect of a smoking intervention programme using the nicotine patch. ${ }^{4}$

\section{Method}

DESIGN

The CEASE trial was a placebo controlled, double blind study that used transdermal nicotine patches as an adjunct to smoking cessation advice in the chest clinic. Subjects who had been smoking $\geqslant 15$ cigarettes/day for at least three years were recruited from the general population on a voluntary basis and randomly allocated to one of five treatment arms, four with nicotine and one with placebo. The four active treatment arms applied different dosages and durations of treatment. All active treatments were followed by a tapering off period of one month. Details of the study protocol and success rates of each treatment arm one year after enrollment have been published elsewhere. ${ }^{4}$ In the present paper we examine the role of sociodemographic factors as predictors of sustained smoking cessation in the CEASE trial.

SMOKING CESSATION INTERVENTION

Following advertising in local media, smokers aged $20-70$ years were recruited at 36 centres in 17 European countries. ${ }^{4}$ Participants had to have made at least one prior attempt to quit. Exclusion criteria were acute cardiac disease within the last three months, pregnancy, breast feeding, current psychiatric disease, alcohol or any other drug abuse, eczema or malignant disease. 
At baseline subjects were required to stop smoking completely on the target day for quitting, and they received a brochure containing advice on smoking cessation and nicotine patch therapy. Subjects in the treatment groups used nicotine patches containing $0.83 \mathrm{mg} / \mathrm{cm}^{2}$ of nicotine for 16 hours (Nicorette, Pharmacia and Upjohn, Helsingborg, Sweden). ${ }^{7}$ Subjects in the placebo group received the same patches without nicotine. Strong advice on refraining from smoking was given at the seven scheduled follow up visits.

\section{MEASUREMENTS}

At enrollment, subjects who entered the study answered a questionnaire that included questions on age, sex, parental smoking, age when cigarette use started, current number of cigarettes smoked per day, previous attempts to quit, presence of other smokers in the household, and former and current diseases. Furthermore, the following measurements were performed: (1) carbon monoxide (CO) concentration in expired air after 15 seconds of breath holding (Bedfont Monitor, Sittingbourne, UK); (2) Fagerström test for nicotine dependence (FTND) (score 0-10 reflecting least to most dependence) ${ }^{8}$; and (3) plasma nicotine and cotinine concentrations, analysed using gas chromatography. ${ }^{9}$ Self-reported cigarette consumption and expired $\mathrm{CO}$ were also measured at all follow up visits, because the outcome variable was sustained abstinence, defined as self-defined complete abstinence from week 2 to month 12, with an expired CO $<10$ parts per million (ppm) at visit 2 and all following visits. Subjects who did not fulfil these criteria were considered failures, as were subjects who did not attend all follow up visits.

Socioeconomic status was measured at baseline using a questionnaire covering housing conditions, education, and employment. Housing conditions included questions about rented or owned home (scoring 0 and 1, respectively), number of years in the present home (ordinal variable categorised as $0-1,2-4$, $5-10$, and $>10$ ) and person per room ratio (ordinal variable with four categories from more to fewer persons per room). A composite variable for housing conditions was also created by combining the answers to these three questions. Education was recorded as the education level attained when schooling was finished (ordinal variable categorised as primary, secondary/high school, higher than secondary/ high school, and postgraduate). Employment was recorded as unemployed or employed and occupation as blue collar and white collar.

ANALYSIS

Although there were large differences in the overall outcome across the 36 centres participating in the study, there was no significant heterogeneity between them in terms of success rate of active versus placebo treatment, as reported elsewhere ${ }^{4}$; accordingly, all analyses were conducted on the pooled data from all centres.
The main outcome variable was sustained smoking cessation. The possible predictors of sustained smoking cessation were age, sex, parental smoking (categorised as absent or present), age when smoking started (ordinal variable with four categories), number of smoked cigarettes per day (ordinal variable categorised as $\leqslant 20,21-30$ or $>30$ ), number of attempts to quit (continuous variable), respiratory, cardiac or other chronic diseases, history of depression, presence of other smokers in the household (all five variables categorised as absent or present), socioeconomic status (housing conditions, education, employment and occupation), baseline expired CO (ordinal variable categorised as $0-20$, 21-40 or $>40$ ppm), FTND score, and blood nicotine and cotinine concentrations (all three expressed as continuous variables). A descriptive analysis was performed first, with categorical variables expressed as proportions and continuous variables as mean (SD) unless specified. After that, occupation was discarded for the analysis because of insufficient data available to classify the subject as blue or white collar in one third of the population sample. Inferential statistical analysis was then performed, considering the main outcome as the dependent variable and the specified predictors as independent variables. Success rates obtained for the studied predictors were calculated and univariable logistic regression models were created. Variables that showed significance $(p<0.10)$ in the univariable models were entered in a multivariable stepwise multiple logistic regression model to determine the odds ratios (OR) and 95\% confidence intervals $(95 \% \mathrm{CI})$ for sustained abstinence of the different predictors. Considering the colinearity between FTND score, baseline expired $\mathrm{CO}$, and blood nicotine/cotinine concentrations, only the variable showing the strongest association with the outcome was included in the multivariable model. All statistical tests were two sided, and a probability value of $p \leqslant 0.05$ was reported as significant. The study was approved by the ethics committee of every institution.

\section{Results}

After a follow up of 12 months, 477 of the 3575 smokers enrolled in the study were sustained abstainers (overall success rate $13.3 \%)$. The descriptive characteristics of the population sample are reported in tables 1 and 2 , together with the success rates for specific subgroups.

When the different predictors of sustained abstinence were assessed in univariable logistic regression models (table 3), a clear cut effect of

Table 1 Descriptive statistics: continuous variables ( $n=$ 3575)

\begin{tabular}{lrr}
\hline & Mean & \multicolumn{1}{c}{$S D$} \\
\hline Age (years) & 40.7 & 10.0 \\
Age started smoking (years) & 16.8 & 3.8 \\
Fagerström test for nicotine & & \\
$\quad$ dependence (score) & 4.7 & 1.3 \\
Blood nicotine (ng/ml) & 15.1 & 9.0 \\
Blood cotinine (ng/ml) & 270.5 & 112.5 \\
\hline
\end{tabular}


Table 2 Descriptive statistics: categoric variables $(n=$ 3575)

\begin{tabular}{|c|c|c|}
\hline & $n(\%)$ & $\begin{array}{l}\text { \% sustained } \\
\text { abstinence }\end{array}$ \\
\hline \multicolumn{3}{|l|}{ Nicotine patch } \\
\hline Active & $2861(80.0)$ & 14.2 \\
\hline Placebo & $714(20.0)$ & 9.9 \\
\hline \\
\hline Female & $1723(48.2)$ & $\begin{array}{l}13.1 \\
11.4\end{array}$ \\
\hline Parental smoking (present) & $2863(80.1)$ & 13.2 \\
\hline \multicolumn{3}{|l|}{ Cigarettes per day } \\
\hline$\leqslant 20$ & $1492(41.7)$ & 15.1 \\
\hline $21-30$ & $1323(37.0)$ & 13.6 \\
\hline$>30$ & $760(21.3)$ & 9.5 \\
\hline Respiratory disease (present) & $1551(43.4)$ & 11.9 \\
\hline Cardiac disease (present) & $248(6.9)$ & 6.8 \\
\hline Other chronic disease (present) & $586(16.4)$ & 13.0 \\
\hline History of depression (present) & $367(10.3)$ & 11.4 \\
\hline \multicolumn{3}{|l|}{ Other smokers in household } \\
\hline (present) & $1784(49.9)$ & 13.5 \\
\hline \multicolumn{3}{|l|}{ Socioeconomic status } \\
\hline \multicolumn{3}{|l|}{ Housing conditions } \\
\hline No & $1602(44.8)$ & 10.4 \\
\hline Yes & $1973(55.2)$ & 15.8 \\
\hline \multicolumn{3}{|l|}{ Years in current home } \\
\hline $0-1$ & $512(14.3)$ & 9.6 \\
\hline $2-4$ & $798(22.3)$ & 11.6 \\
\hline $5-10$ & $1042(29.1)$ & 13.7 \\
\hline$>10$ & $1223(34.2)$ & 15.8 \\
\hline \multicolumn{3}{|l|}{ Education ${ }^{\star}$} \\
\hline Primary school & $18(0.5)$ & 16.7 \\
\hline Some secondary/high school & $1114(32.3)$ & 12.5 \\
\hline \multicolumn{3}{|l|}{ Higher than secondary/high } \\
\hline Postgraduate studies & $170(4.9)$ & 14.7 \\
\hline \multicolumn{3}{|l|}{ Employment* } \\
\hline Unemployed & $618(17.9)$ & 13.7 \\
\hline Employed or self employed & $2826(82.1)$ & 13.2 \\
\hline \multicolumn{3}{|l|}{ Expired CO (ppm) } \\
\hline $0-20$ & $1367(38.2)$ & 16.6 \\
\hline $21-40$ & $1835(51.3)$ & 11.7 \\
\hline$>40$ & $373(10.5)$ & 9.6 \\
\hline
\end{tabular}

^Available from 3444 subjects. CO, carbon monoxide.

active nicotine patch treatment on the success rate was observed (OR 1.50, 95\% CI 1.15 to 1.96). Age and sex were also predictors of sustained smoking cessation, with higher success rates in older subjects and men. Smokers with respiratory or cardiac disease had lower success rates when compared with smokers not suffering these diseases. A negative effect of other chronic diseases or a history of depression was not evident in the study, however. The number of cigarettes consumed per day was a clear predictor of sustained abstinence, with a higher success rate when the subject smoked less cigarettes per day. This effect was also evident when biochemical markers of tobacco use were examined, with a highest probability of sustained abstinence associated with lower concentrations of expired $\mathrm{CO}$, and blood nicotine and cotinine. Similarly, the FTND score also predicted sustained abstinence, with an increase in success rate for smokers with lower scores. Housing conditions, considered to be a marker of income and social factors, were strong socioeconomic predictors of success, with higher success rates for smokers who owned their houses, had longer residence periods in their households, and fewer persons per room. The other socioeconomic variables assessed in our study, educational level and employment, were not clinically significant determinants of success, however. When all significant predictors of the outcome were assessed in a multivariable model, the associations observed in the univariable models did not change significantly, and nicotine treatment, age, sex, cigarettes per day, cardiorespiratory disease, housing conditions, and expired CO persisted as significant predictors of smoking cessation for the population sample who volunteer to participate in the CEASE trial (table 3).

\section{Discussion}

In the present study age, sex and housing conditions emerged as clear cut predictors of

Table 3 Predictors of sustained smoking cessation

\begin{tabular}{|c|c|c|c|c|}
\hline & Crude OR $(95 \% C I)$ & $p$ Value & Adjusted OR $(95 \% C I)^{*}$ & p Value \\
\hline Nicotine patch & $1.50(1.15$ to 1.96$)$ & $<0.01$ & $1.47(1.11$ to 1.96$)$ & $<0.01$ \\
\hline Age (categorised as decades) & $1.02(1.01$ to 1.03$)$ & $<0.001$ & $1.17(1.03$ to 1.31$)$ & $<0.05$ \\
\hline Sex (men $v$ women) & $1.38(1.14$ to 1.68$)$ & $<0.001$ & $1.52(1.22$ to 1.88$)$ & $<0.001$ \\
\hline Age started smoking & $1.00(0.98$ to 1.03$)$ & NS & - & - \\
\hline Parental smoking $\dagger$ & $0.99(0.76$ to 1.28$)$ & NS & - & - \\
\hline Cigarettes per day (categorised) & $0.79(0.69$ to 0.90$)$ & $<0.001$ & $0.80(0.69$ to 0.93$)$ & $<0.01$ \\
\hline Number attempts to quit & $0.99(0.96$ to 1.02$)$ & NS & - & - \\
\hline Respiratory disease $\dagger$ & $0.79(0.67$ to 0.92$)$ & $<0.01$ & - & - \\
\hline Cardiac diseaset & $0.46(0.28$ to 0.75$)$ & $<0.01$ & - & - \\
\hline Respiratory or cardiac disease $\dagger$ & $0.73(0.60$ to 0.89$)$ & $<0.001$ & $0.75(0.60$ to 0.93$)$ & $<0.01$ \\
\hline Other chronic diseaset & $0.95(0.73$ to 1.24$)$ & NS & - & - \\
\hline History of depression $t$ & $0.82(0.59$ to 1.15$)$ & NS & - & - \\
\hline Other smokers in household $\dagger$ & $1.03(0.85$ to 1.25$)$ & NS & - & - \\
\hline \multicolumn{5}{|l|}{ Socioeconomic status } \\
\hline \multicolumn{5}{|l|}{ Housing conditions } \\
\hline Owned home & $1.62(1.32$ to 1.98$)$ & $<0.001$ & _- & - \\
\hline Years in present home & $1.20(1.09$ to 1.32$)$ & $<0.001$ & - & - \\
\hline Composite housing variable $\ddagger$ & $1.43(1.25$ to 1.65$)$ & $<0.001$ & $1.29(1.11$ to 1.51$)$ & $<0.001$ \\
\hline Education & $1.09(0.91$ to 1.30$)$ & NS & - & - \\
\hline Employment & $0.96(0.74$ to 1.23$)$ & NS & - & - \\
\hline Test for nicotine dependence & $0.92(0.86$ to 0.99$)$ & $<0.05$ & - & - \\
\hline Expired CO & $0.98(0.97$ to 0.99$)$ & $<0.001$ & $0.86(0.77$ to 0.94$)$ & $<0.01$ \\
\hline Blood nicotine (unit/10) & $0.98(0.97$ to 0.99$)$ & $<0.01$ & - & - \\
\hline Blood cotinine (unit/100) & $0.99(0.99$ to 1.00$)$ & $<0.01$ & - & - \\
\hline
\end{tabular}

${ }^{\star}$ Multivariable model adjusted for all predictor variables showing an association with the outcome variable $\mathrm{p}<0.10$. Respiratory and/or cardiac disease was included in the model as a single variable. Housing conditions were included in the model as composite variable. Test for nicotine dependence and blood nicotine/cotinine were not included in the model because of colinearity with expired carbon dioxide $(\mathrm{CO})$.

†Present $v$ absent.

¥Housing conditions as a composite variable including owned home, years in present home, and person per room ratio (see text for details). 
smoking cessation for the subjects who volunteer to participate in a European smoking cessation intervention programme, with higher success rates for males and older subjects who owned their home and have longer residence periods in their household. Sustained abstinence emerged to be more difficult for subjects who have developed cardiopulmonary disease. Certain markers of tobacco use also proved to be associated with success: subjects smoking more cigarettes with high $\mathrm{CO}$ concentrations in expired air attained smoking cessation less often.

Several studies have shown that age and sex are important determinants of smoking cessation in the general population. Higher success rates have been commonly reported for older subjects, ${ }^{151011}$ and age has been currently considered a main confounder when other predictors of smoking cessation were analysed. ${ }^{12}$ Differences in smoking prevalence according to sex have been reported in Europe and North America in the last decades, together with higher smoking cessation rates in men, probably related both to differences of conditioning effects and nicotine dependence patterns between the sexes. ${ }^{1{ }^{12-14}}$ Some specific characteristics of smoking cessation in women have emerged clearly from the studies that have examined cessation during pregnancy, often showing lower than expected long term success rates. ${ }^{15}$

Sociodemographic characteristics may have a greater impact on smoking cessation in smokers who volunteer to be included in intervention programmes than in the general population. In fact, subjects participating in smoking cessation programmes often are not representative of the general population. As we have shown in our study, more than $60 \%$ of smokers enrolled in the CEASE trial had followed education beyond secondary/high school, suggesting that the population participating in smoking cessation intervention programmes is self-selected, with an under representation of subjects with primary education. This selection determines that predictors of success in intervention programmes may be different from predictors for the general population. In the Lung Health Study, a clinical trial that enrolled approximately 4000 subjects in an intensive smoking intervention programme, a sex difference in the one year smoking cessation rates was not observed, but a higher relapse rate for women emerged three years after the intervention. ${ }^{16}$ Similarly, in our study we have found a higher success rate for men, evident one year after the intervention, that persisted after adjusting for covariates (OR $1.52,95 \%$ CI 1.22 to 1.88$)$. These two observations suggest that success in smoking cessation programmes is more difficult for women than for men, a difference that health care planners need to take into account.

Socioeconomic status is usually considered to be derived from a combination of education, income, and occupation, ${ }^{17}{ }^{18}$ but the way to measure these components has not been standardised, and different approaches to its measurement may be the cause of the reported

\section{What this paper adds}

Age, sex, socioeconomic status, and nicotine dependence are well defined determinants of success in smoking cessation for the general population, but the impact of sociodemographic factors on success rates has been rarely investigated for participants in smoking intervention programmes.

This study shows that European smokers who volunteer to participate in smoking cessation programmes are a self-selected population with over representation of subjects with higher education. The use of nicotine patches improved success rates for this population, but smoking cessation also depends greatly on age, sex, and certain socioeconomic factors. Higher success rates may be expected in males and older subjects with better housing conditions. Sustained smoking cessation was especially difficult for subjects who consumed more tobacco and had developed cardiorespiratory disease.

differences in the impact of socioeconomic status on health variables. ${ }^{19} \mathrm{~A}$ high impact of some housing related components of socioeconomic status on smoking cessation emerged from our study, with higher success rates associated with better housing conditions (OR 1.29, 95\% CI 1.11 to 1.51$)$. Subjects who owned their home, had a low person per room ratio, and lived in the same household for longer periods were more often successful. Other components of socioeconomic status, however, did not seem to have the same impact on smoking cessation in our study. Education had no impact on the outcome, perhaps because of the difficulty of applying educational categories that are meaningful across countries with different educational systems, or because of under representation of subjects with primary studies in the CEASE trial. Our results suggest that the effect of education on smoking cessation may be low for subjects participating in intervention programmes, because subjects who attained higher education levels are over represented in the population who volunteered to participate. In population based studies higher education has been a predictor of success in smoking cessation, ${ }^{5102021}$ and this effect of education has also been reported in some intervention studies. ${ }^{22}$ In our study we have not found an effect of employment on smoking cessation, a finding similar to those of other studies that have not reported a significant impact of unemployment on the change in smoking habits. $^{23}$

Several factors related to nicotine dependence were associated with success. Subjects who smoked fewer cigarettes per day and had lower concentrations of the biochemical markers of tobacco use (expired $\mathrm{CO}$ and blood cotinine/nicotine) had higher success rates, as has been reported by other authors. ${ }^{51021}$ Subjects with respiratory and/or cardiac diseases had lower success rates, and these diseases may probably be considered in some way 
markers of dependence, because subjects with low nicotine dependence often quit shortly after the first appearance of smoking related symptoms, not allowing for the progression to chronic disease. The difficulty in refraining from smoking has been also reported for the smokers with respiratory symptoms who enrolled in the Lung Health Study. ${ }^{22}$

The FTND score was a less powerful predictor of sustained abstinence than biochemical markers of tobacco use such as expired CO. The FTND has been validated against objective measures of tobacco use ${ }^{8}$ but it is not unexpected that it correlates less well with success than do other measures of tobacco use. ${ }^{24}$ In fact, the main advantage of the FTND is that it can be used easily in the clinic without any blood sampling or use of complementary devices. The low predictive power of dependence questionnaires for smoking cessation, previously reported by other authors, ${ }^{3}$ emphasises the need to use objective measures when a prediction of success in smoking cessation is looked for.

Some studies have reported the impact of cohabiting with non-smokers in smoking cessation. ${ }^{15152025}$ This effect, however, was not observed in our study. This may be related to the inclusion of a wider set of predictors in the present analysis, which probably revealed the low predictive power of partner smoking when other explicative variables are included in the analysis.

We conclude that European smokers who volunteer to participate in smoking cessation programmes are a self-selected population with over representation of subjects who attained an education level higher than secondary/high school. The use of nicotine patches improves the success rate, but smoking cessation also depends greatly on age, sex, and certain socioeconomic factors. Higher success rates after one year of intervention may be expected in males and older subjects with better housing conditions. Sustained smoking cessation is especially difficult for subjects who consume more tobacco or have developed cardiorespiratory disease.

1 Hymowitz N, Cummings KM, Hyland A, et al. Predictors of smoking cessation in a cohort of adult smokers followe
for five years. Tobacco Control 1997;6(suppl 2):S57-62.
Graham H. Smoking prevalence among women in the

European Community 1050-1990. Soc Sci Med 1996; 43:243-53.
3 Kenford SL, Fiore MC, Jorenby DE, et al. Predicting smoking cessation. Who will quit with and without the nicotine patch. ҒAMA 1994;271:589-94.

4 Tonnesen P, Paoletti P, Gustavsson G, et al. Higher dosage nicotine patches increase one-year smoking cessation rates: results from the European CEASE trial. Eur Respir $\mathcal{F}$ 1999;13:138-246.

5 Osler M, Prescott E. Psychosocial, behavioural, and health determinants of successful smoking cessation: a longitudi-

6 Farkas AJ, Pierce JP, Zhu SH, et al. Addiction versus stages of change models in predicting smoking cessation. Addiction 1996;91:1271-80.

7 Palmer KJ, Buckley MM, Faulds D. Transdermal nicotine: a review of its pharmacodynamic and pharmacokinetic properties, and therapeutic efficacy

8 Heatherton TF, Kozlowski LT, Frecker RC, et al. The Fagerstöm test for nicotine dependence: a revision of the Fagerström tolerance questionnaire. Br f Addiction 1991; 86:1119-27.

9 Stapleton JA, Russell MAH, Feyerabend C, et al. Dose nicotine patches in general practice. Addiction 1995;90:3142 .

10 Tillgren P, Haglung BJ, Lundberg M, et al. The sociodemographic pattern of tobacco cessation in the 1980s: results graphic pattern of tobacco cessation in the 1980 s: results
from a panel study of living condition surveys in Sweden. from a pademiol Community Health 1996;50:625-30.

11 Hatziandreu EJ, Pierce JP, Lefkopoulou M, et al. Quitting smoking in the United States in 1986. F Natl Cancer Inst 1990;82:1402-6.

12 Fiore MC, Novotny TE, Pierce JP, et al. Trends in cigarette smoking in the United States. The changing influence of gender and race. $\mathcal{F A M A}$ 1989;261:49-55.

13 Pierce JP, Fiore MC, Novotny TE, et al. Trends in cigarette smoking in the United States. Projections to the year 2000. fAMA 1989;261:61-5.

14 Pierce JP, Fiore MC, Novotny TE, et al. Trends in cigarette smoking in the United States. Educational differences are increasing. FAMA 1989;261:56-60.

15 Severson HH, Andrews JA, Lichtenstein E, et al. Predictors of smoking during and after pregnancy: a survey of mothof smoking during and after pregnancy: a
ers of newborns. Prev Med 1995;24:23-8.

16 Bjornson W, Rand C, Connet JE, et al. Gender differences in smoking cessation after 3 years in the lung health study. Am F Public Health 1995;85:223-30.

17 Winkleby MA, Jatulis DE, Frank E, et al. Socioeconomic status and health: how education, income, and occupation contribute to risk factors for cardiovascular disease. $A m \mathcal{F}$ Public Health 1992;82:816-20.

18 Latour Perez J, Alvarez-Dardet Díaz C. La medición del nivel socioeconómico. Med Clin (Barc) 1989;92:470-5.

19 Hemingway H, Nicholson A, Stafford M, et al. The impact of socioeconomic status on health functioning as assessed by the SF-36 questionnaire: the Whitehall II study. $A m \mathcal{F}$ Public Health 1997;87:1484-90.

20 Olsen J. Predictors of smoking cessation in pregnancy. Scand f Soc Med 1993;21:197-202.

21 Hymowitz N, Sexton M, Ockene J, et al. Baseline factors associated with smoking cessation and relapse. MRFIT research group. Prev Med 1991;20:590-601.

22 Nides MA, Rakos RF, Gonzales D, et al. Predictors of initial smoking cessation and relapse through the first 2 years of

23 Morris JK, Cook DG, Shaper AG. Non-employment and changes in smoking, drinking, and body weight. BMF changes in smokin

24 Jarvis MJ, Tunstall-Pedoe H, Feyerabend C, et al. Comparison of tests used to distinguish smokers from nonsmokers. Am $\mathcal{F}$ Public Health 1987;77:1435-8.

25 Tillgren $\mathrm{P}$, Haglung BJ, Ainetdin T, et al. Who is a successful quitter? One-year follow-up of a national tobacco quit and win contest in Sweden. Scand F Soc Med 1995;23:193201. 